\title{
Audio Digital (Características)
}

\section{Digital Audio (Features)}

\section{María del Pilar Gómez Ortiz ,, ${ }^{*}$ Eduardo Vázquez Domínguez²}

\begin{abstract}
:
Nowadays the production, development and exchange of audios is something very daily, that is because they have created a number of formats or containers, some of which not only group audio data, but audio and video, on the other hand, not all audios can be heard using the same player.

Considering this constant use of audio formats, we present a mental map through which we highlight the properties of the code (algorithm that encodes and decodes data), associated with the different formats, among the features that will be highlighted are the formats that are taxed without data compression, those that perform a compression without loss of data and those that perform a compression with loss of data, characteristics that are important to know since depending on knowing the peculiarities of each format, we can determine which is the most convenient according to the characteristics that we want from our audios.
\end{abstract}

\section{Keywords:}

Audio, compression, de-coding. Formats

\section{Resumen:}

Hoy en día la producción, desarrollo e intercambio de audios es algo muy cotidiano, es por ello que se han creado un sin número de formatos o contenedores, algunos de los cuales no solo agrupan datos de audio, sino de audio y video, por otro lado, no todos los audios se pueden escuchar usando el mismo reproductor.

Considerando este uso constante de formatos de audio, presentamos un mapa mental a través del cual destacamos las propiedades del códe (algoritmo que codifica y decodifica datos), asociado a los distintos formatos, entre las características que se estarán destacando se encuentran los formatos que gravan sin compresión de datos, los que realizan una compresión sin pérdida de datos y aquellos que realizan una compresión con pérdida de datos, características que son importantes de conocer ya que en función de saber las peculiaridades de cada formato podemos determinar cuál es el más conveniente de acuerdo a las características que queremos de nuestro audios.

\section{Palabras Clave:}

Audio, compresión, de-codificación. formatos

\footnotetext{
${ }^{1}$ Profesora por asignatura en el Programa Bachillerato General, Escuela superior de Tepeji del Rio, Av. Del Maestro No. 41 Colonia Noxtongo $2^{\text {a }}$ Sección, Tepeji del Rio, Hidalgo, México.Correo mapili_30@ hotmail.com

${ }^{2}$ Profesor por asignatura en el Programa Bachillerato General, Escuela superior de Tepeji del Rio, Av. Del Maestro No. 41 Colonia Noxtongo $2^{a}$ Sección, Tepeji del Rio, Hidalgo, México.Correo evd_2000@yahoo.com.mx.
} 


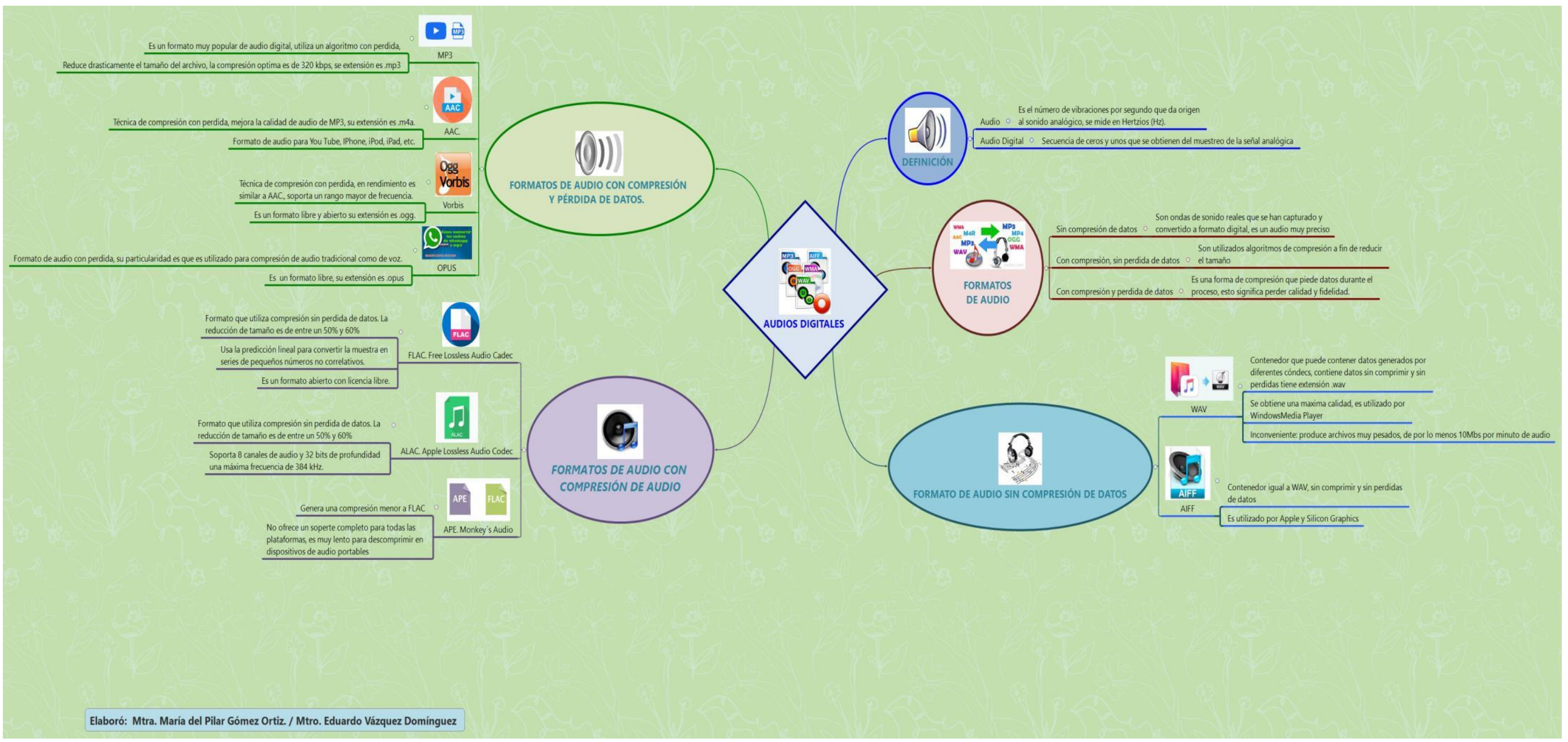




\section{Referenclas}

Ministerio de Educación, Política Social y Deporte (s.f).

Diseño de materiales multimedia. Web 2.0,

Audio: introducción. Recuperado el 6 febrero

De: http://www.ite.educacion.es/formacion/mat

eriales/107/cd/audio/pdf/audio01.pdf

* Wikiversidad (s/f) Formatos y procesamientos de

música y sonido. Recuperado en enero de 2019

De

https://es.wikiversity.org/wiki/Formatos y proce samiento de m\%C3\%BAsica y sonido

Tecnologías para Sistemas Multimedia (2004). Tema 3

Audio, Recuperado en enero 2019

De

http://dis.um.es/ ifernand/0405/tsm/tema3.pdf 